\title{
A tecnologia e a evolução podem levar a comunicação para a esfera das mentes
}

\section{Technology and evolution may lead communication to the mind sphere}

Sebastião Carlos Squirra

Professor Doutor do Programa de Pós-graduação em Comunicação, Faculdade de Comunicação, Universidade Metodista de São Paulo (UMESP).

<ssquirra@gmail.com>

\section{RESUMO}

A submersão tecnológica redefine as individualidades na vida virtualizada, onde a comunicação entre homens e máquinas se efetiva com interatividades elétricas, por interfaces com toques e movimentos físicos, comandos orais ou através dos olhos. Na neurociência máquinas passaram a entender instruções a partir de mensagens produzidas pelo cérebro humano. Neste texto, intentamos mostrar que isto tem muita relevância para as comunicações e, entendendo o atual momento como o da tecnosfera, se investiga até que ponto as inovações levarão o campo da comunicação para a noosfera. O objetivo é o de, baseado em bibliografia específica, refletir se as reconfigurações alterarão o processo de produção, acesso e consumo de mensagens comunicativas.

\section{ABSTRACT}

\begin{abstract}
Technological submersion resets the individualities in a virtualized life where communication between men and machines effectives with electric interactivity, by interfaces with touches and physical movements, oral commands or through the eyes. In neuroscience machines come to understand instructions deriving from messages produced in the human brain. In this paper, we point out that this is very relevant for communications and understanding the present moment as the technosphere, we investigated the extent to which innovations will lead the communication field to the noosphere. The goal is to, based on specific literature, reflect on whether the reconfiguration alter the production process, access and consumption of communicative messages.
\end{abstract}

Keywords: Digital media. Cybernetics. Noosphere.

"[...] os computadores se tornarão embutidose
integrados nos corpos e cérebros da espécie".

Ray Kurzweil (2007, p.344)

\section{Introdução}

Turbinada por inúmeras inovações tecnológicas, a experiência humana vem sofrendo alterações cognitivas e sensoriais significativas em número e densidade nas últimas décadas. Compulsoriamente, o ser contemporâneo mergulhou em realidade cujo cotidiano espelha vida em plenitudes tecnológicas inéditas e onde as interações se materializam em plataformas comunicativas, em aplicativos digitais, em sistemas de redes com aparatos o tempo todo 
conectados e, presencial ou virtualmente, os seres dialogam com máquinas a partir de comandos ainda desferidos pelos dedos, fazendo com que a internet em todas as coisas ${ }^{1}$ seja experiência concreta.

Dessa forma, ao observar o entorno e visualizar as imersões tecnológicas em que todos se encontram, resgatamos o escritor H.G. Wells que, em 1938 publicou o livro Cérebro mundial (World brain). Nesta obra, Wells, projetava um tempo em que as "pessoas no planeta poderiam ter acesso fácil a todos os pensamentos e conhecimentos" (Carr, 2012, p.54-60). Objetivamente, este autor vislumbrou que uma World Wide Web, uma rede mundial de computadores, iria se viabilizar décadas à frente. Hoje imersos em tal realidade, entendemos que a realidade tecnológica se tornou compulsória, pois é constante a incorporação de chips nos bens de consumo e acesso. Tal alargamento estende os sentidos humanos para uma inédita dimensão física (ampliação dos conceitos individuais de espaço, tempo e de potência de ação nestes) e cognitiva (múltiplas formas de armazenamento e acesso ao conhecimento). E também na relação do homem consigo próprio, uma vez que permite que, ao ter mais recursos técnicos, este deverá libertar-se das atividades mecanizadas, podendo dedicar tempo para a compreensão das razões da sua existência e nela imergir. Lembramos que o conceito de alma esteve presente nas reflexões de vários cientistas renomados, entre eles, Einstein, Leibnitz e Norbert Wiener. No livro, Cibernética e Sociedade - o uso humano de seres humanos, ao definir o termo homeostase como o "processo pelo qual nós, seres vivos, resistimos ao fluxo geral de corrupção e desintegração" (Wiener,1954, p.94), Wiener (1954, p.97) afirma que "a religião cristã e seus antecedentes mediterrânicos [...] incorporaram a noção de alma", lembrando que "a mais interessante das primeiras explicações científicas da continuidade da alma é a de Leibnitz, que concebe a alma como pertencente a uma classe mais vasta de substâncias espirituais permanentes, a que deu o nome de mônadas" (Wiener ,1954, p.98). Esse conceito é interessante, mas complexo, tendo sido abordado por vários escritores e está presente na obra $A$ Física da alma (2008), do físico quântico Amit Goswami, porém, extrapola o foco da presente reflexão.

Teóricos sinalizam que a sociedade está imersa em espécie de caldo tecnológico que se tornou integrado ao meio ambiente. Esta condição se inseriu e se adensou com a Revolução Industrial, conforme mostram alguns autores (Toffler,1980; Gama, 1986; Bell,1989), para quem as adoções técnicas vêm definindo a sociedade e alterando os processos produtivos. Tal dimensão

1 Ampliação do conceito de "internet das coisas" (loT, Internet of things) 
constitui o que tem sido definido como tecnosfera, como bem tratado por vários autores (Ferrara, 2007; Santos, 2008). Na obra Semiótica da cultura e semiosfera (2007) organizada por Irene Machado consta o texto A circularidade do conhecimento de Lucrécia D’Alessio Ferrara, autora que apresenta a concepção do escritor Jorge Luis Borges que aborda o conceito esfera, termo que originou outros tantos, como barisfera (núcleo metálico terrestre), litosfera (camada de rochas do globo), hidrosfera (camada de água), biosfera (evolução biológica) e atmosfera (camada do ar). E ainda: antroposfera (o ser humano), ecosfera (existência da vida), iconosfera (representação visual), blogosfera (comunidades virtuais), infosfera (entidades informacionais), ciberesfera (conhecimento), e ideosfera (evolução dos pensamentos, teorias e ideias). Importante lembrar o conceito de esfera pública apresentado por Habermas no livro Mudança estrutural da esfera pública (Habermas, 2014). Mas, um conceito especial nos interessa destacadamente, o de tecnosfera. Depois de definir este neologismo, Milton Santos apresenta o termo psicosfera como "o mundo das ideias, crenças, paixões e lugar da produção de um sentido, também faz parte da produção deste ambiente, desse entorno da vida, fornecendo regras à racionalidade ou estimulando o imaginário" (Santos, 2008, p.256). Tais reflexões endereçam o conceito de ideosfera, que recorta a "evolução mimética, aquela elaborada e residente no interior das mentes, com a seleção natural de pensamentos, teorias e ideias" (Wikipedia, 2014). Estas definições nos orientam na direção de olhar as inúmeras transformações por que passa a comunicação na contemporaneidade.

\section{Tecnologizações e noosfera}

Entendida como sequência conceitual da tecnosfera, a noosfera se apresenta como fruto da evolução cognitiva humana, sentido quese exponenciou com a força massiva da midiosfera (suportes midiáticos), conceito abordado por João Artur Izzo (2009). Centrado na teoria de Vernadsky, o paleontológico, filósofo e jesuíta francês Pierre Teilhard de Chardin define o conceito de noosfera como a "esfera do pensamento humano" sendo que este entendeu o termo como o $4^{\circ}$ degrau da evolução humana, em sequencia à geosfera, a biosfera e a tecnosfera. Para Chardin, primeiro ocorreu a cosmogênese (criação do universo), em seguida, da não-vida surgiu a vida, a biogênese (esfera da vida) e, a partir da consciência de si mesmo realizada pelo homem, ao unir corpo e espírito, chegase à noogênese, situação na qual o homem migra para as realidades mentais. Entre outros autores, essa transição está analisada no texto Teilhard de Chardin: a ideia de evolução e vida pessoal (1999), de Fábio de Barros Silva. 
Para Morin (2001, p.143), "a noosfera não é apenas o meio condutor/ mensageiro do conhecimento humano. Produz, também, o efeito de um nevoeiro, de tela entre o mundo cultural, que avança cercado de nuvens, e o mundo da vida", trazendo a questão da inteligência coletiva, característica que surge com os sistemas complexos, virtuaise globalizados da contemporaneidade. Como diz Morin (2001), as "coisas do espírito" (tradições, mitos, ideologias etc.) possuem autonomia, se reproduzem, se reconstituem, se reelaboram. Para ele, "as ideias são dotadas de vida própria porque dispõem, como os vírus, de um meio (cultural/cerebral) favorável da capacidade de auto-nutrição e de autoreprodução" (Morin, 2001, p.138). Nos são muito úteis estes conceitos, pois no momento atual as hibridizações tecnológicas estão sendo expandidas em todas as direções da singularidade humana e tudo se concretiza em interações em múltiplos displays. Tal realidade alterou espacialidades, eliminou distâncias e desconstruiu a sensação de tempo, inserindo o homem em dimensão que tudo reconfigura continuamente e compondo nível inédito para o ato de ver televisão, ouvir rádio, ler jornais e periódicos, dialogar em aparelhos de telefonia, fazer compras, trocar correspondências, se relacionar amorosamente etc.

Esta multiplicidade midiática requer processo forte de interação entre o ser e a máquina, a partir da inserção de comandos apropriados e na lógica instrumental dos aparelhos. O físico Marcelo Gleiser lembra que a "realidade resulta da forma integrada de incontáveis estímulos coletados pelos cinco sentidos, captados do mundo exterior e transportados para nossas cabeças pelo sistema nervoso", adicionando que "eu sou e você é uma rede eletroquímica autossustentável" (Gleiser, 2011, p.C9). As redes são pressupostos essenciais para a dimensão cibernética e ao acessá-las os seres dinamizam as muitas formas de atracamentos na promoção do conhecimento. Dessa forma, reconfigurada pela evolução tecno-cognitiva dos dias atuais, desponta a possibilidade de o ser humano estar integrando uma imperceptível rede tecnocerebral coletiva. Esta se delinearia como um gigantesco sistema de conexões que, mediado por tecnologias ubíquas e persistentes, estaria viabilizando uma internet "de mentes", indo além da internet "de e das coisas". Isto, pois como Kurzweil afirma

[... ] a inteligência da máquina irá superar a inteligência humana [...] as implicações incluem a fusão da inteligência biológica e não biológica, software humano e ultra altos níveis de inteligência que se expandem no universo na velocidade da luz" (Kurzweil, 2001, tradução do autor) $)^{2}$.

2 Tradução para "Within a few decades, machine intelligence will surpass human intelligence, leading to The Singularity - technological change so rapid and profound it represents a rupture in the fabric 
Tal pressuposto insere o conceito de transhumanismo, onde seres humanos atingirão nível específico de desenvolvimento propiciado pela evolução tecnológica e robótica, no continuo "avanço da nossa relação simbiótica com aparelhos e instrumentos", como diz Gleiser (2014). Este cientista complementa que "nosso cérebro não é mais apenas o que está dentro do crânio, ele espalha seus tentáculos pelo mundo afora" (Gleiser, 2014).

Indo na mesma direção, na obra Decodificando o Universo, Seife (2010, p.237) lembra que "cérebros são máquinas processadoras de informação e estão sujeitos às leis da informação". O autor lembra ainda que

a teoria da informação clássica implica que somos meras máquinas extremamente complexas de processamento de informações. Isso significa que não somos fundamentalmente diferentes de uma máquina de Turing ou de um computador. (Seife, 2010, p.237).

Nesse sentido, autores indicam que as lógicas do pensamento estão nas máquinas e estas conectam os seres em processos onde profunda virtualização é dominante. Os contingentes humanos desenvolveram níveis inéditos de abstração espacial e, para a compreensão da nova dimensão cognitiva, criaram novas linguagens para as confrarias da infosfera em que se encontram circundados. Este processo está levando a humanidade a um novo patamar de experiência sensorial, estabelecendo possibilidades de diálogos que variam da dimensão real àquela metafísica. Corroborando com a reflexão, em artigo para a Carta Capital, Leonardo Boff afirma que "é como se o nosso cérebro começasse a crescer fora da caixa craniana e pelas novas tecnologias penetrasse profundamente nos mistérios da natureza". (Boff, 2009).

Tornou-sepertinenteincorporarestudos da Neurociência,especificamente no segmento da Psicologia Cognitiva. Assim, Sternberg (2013, P. 9) lembra que "no fim da década de 1950, alguns psicólogos estavam intrigados pela incômoda ideia de que as máquinas poderiam ser programadas para demonstrar o processamento inteligente da informação"e diz que os postulados de Shannon e Weaver tinham sido fundamentais nos estudos desses cientistas, afirmando que "a teoria da informação, [...] buscava entender o comportamento das pessoas sobre como elas elaboram os tipos de elementos de informação processada pelos computadores" (Sternberg, 2013, p.10) e lembra que essa área havia sido de grande utilidade no período de guerra e também na publicidade. Sternberg

of human history. The implications include the merger of biological and nonbiological intelligence, immortal software-based humans, and ultra-high levels of intelligence that expand outward in the universe at the speed of light. 
discorre sobre o linguista Noam Chomsky e destaca Alan Turing, para quem "em pouco tempo seria difícil distinguir a comunicação das máquinas da dos seres humanos" (citado por Sternberg, 2013, p.9), define Ciência cognitiva como um "campo multidisciplinarque se utiliza de ideias emétodos da Psicologia Cognitiva, da Psicobiologia, da IA (Inteligência Artificial), da Filosofia, da Linguística e da Antropologia" (2013, p.22), destacando os estudos feitos para entender como "o processamento da informação ocorre no nível celular" (Sternberg, 2013, p.30). Sternberg arremata dizendo que os "neurônios tendem a se organizar em forma de redes que se interligam, trocando informações e promovendo vários tipos de processamento de informação" (2013, p.30).

\section{Redes e neurônios}

Em A teia da vida (1996), Fritjof Capra afirma que "entender ecossistemas será, em última análise, entender redes" e que a "concepção de rede foi a chave para os recentes avanços na compreensão científica não apenas dos ecossistemas, mas também da própria natureza da vida" (Capra, 1996, p.45). Sabe-se que tais postulados integram os estudos da Cibernética ${ }^{3}$, segmento científico no qual Wiener (1954) estruturou pressupostos nas comparações do funcionamento dos organismos e máquinas. Especialmente quando Norbert Wiener afirmou que "é certamente verdade que o sistema social é uma organização semelhante ao indivíduo, que é mantido coeso por meio de um sistema de comunicação" (citado por Capra, 1996, p.63). Sternberg (2013, p.30), acrescenta que "os neurônios tendem a se organizar na forma de redes que se interligam, trocando informações e promovendo vários tipos de processamento da informação". Importante lembrar a contribuição do matemático John von Neumann que, numa das famosas Conferências $\mathrm{Macy}^{4}$, discorreu sobre as analogias entre o computador e o cérebro que, conforme relata Capra faz uso da "lógica matemática para entender o funcionamento do cérebro" (Capra, 1996, p.59).

Na contemporaneidade, o cientista Kurzweil aprofunda estas questões e como autor de The age of intelligent machines e Singularity is near (ambas sem tradução no Brasil) prevê que em momento futuro o homem vai se fundir com a tecnologia (configurando o conceito de transhumano, citado antes). Nesta condição o ser humano terá milhões de nanobots (robôs em escala nanométrica)

3 Apesar de o termo ser atribuído a Norbert Wiener, este aponta Ampère que usou o termo na ciência política. $(1954$, p.15)

4 As The Macy Conferences (EUA, 1946 a 1953), foram encontros científicos interdisciplinares que levaram à criação da cibernética. 
no interior do corpo, em hibridização de inteligências biológica e não-biológica. Em A era das máquinas espirituais (2007), Kurzweil lembra as condições da rede cerebral ao falar que "o cérebro humano possui cerca de 100 bilhões de neurônios. Com uma média estimada de mil conexões entre cada neurônio e seus vizinhos, temos cerca de 100 trilhões de conexões, cada uma capaz de um cálculo simultâneo" (Kurzweil, 2007, p.147). Todavia, na comparação com as máquinas computacionais, adverte que a velocidade dos circuitos neurais humanos é relativamente baixa, pois estes realizam apenas 200 cálculos por segundo (Kurzweil, 2007, p.148). Mas, isto não será problema insolúvel, pois como citado por Ricardo Anderáos, para Kurzweil "haverá uma rede invisível de computadores profundamente integrados no ambiente, em nossos corpos e dentro do nosso próprio cérebro" (Anderáos, 2006, p. L10), sendo que esse jornalista complementa "será difícil saber onde acabam os seres humanos e começam as máquinas" (Anderáos, 2006, p. 10). Neste ponto, residem as-bases da Inteligência Artificial, que apresenta o famoso Teste de Turing experimento que, a partir de uma indagação aleatória não codificada nas memórias da máquina, consiste em comparar a sabedoria de uma determinada resposta, independentemente se ela tenha sido fornecida pelo ser humano ou por uma máquina altamente sofisticada.

\section{Simbioses tecno-biológicas}

Estas são questões que têm chamado a atenção de muitos pesquisadores de cognições, territórios e formações os mais variados, revelando ser imprescindíveis estudos baseados em transversalidades científicas. Assim, em tais iniciativas convergem cientistas de diferentes matizes teóricas, pois como dito antes, sabe-se que as máquinas replicam as lógicas do cérebro e existem dimensões cognitivas nebulosas ainda a ser dimensionadas e compreendidas (Penrose, 1993; Tenório, 2001 e outros). Tal colocação é exemplificada no caso de Michael Chorost, que ao ficar surdo em 2001 teve implantes cocleares inseridos nos ouvidos, conforme relata Sue Halpern no texto Cérebro: no controle ou controlado? (2011). Halpern descreve que Chorost expõe o processo de inserção de dispositivos que fez em seu corpo no texto Reconstruído: como me tornar parte computador fez de mim mais humano (tradução do autor) ${ }^{5}$, sendo que em obra mais recente, Rede mundial de cérebros: a integração vindoura entre humanidade, máquinas e internet (tradução do autor) ${ }^{6}$, Chorost defende a ousada ideia de se

5 Tradução para "Rebuilt: How becoming part computer made me more human."

6 Tradução para "World Wide Mind: The coming integration of humanity, machines and the internet." 
"instalar computadores intracerebrais em todos", o que permitiria que a internet "seria parte integral do ser humano e seu uso seria tão natural quanto o de nossas próprias mãos" (Halpern, 2011).

Neste cenário, as máquinas seriam, inclusive, sensíveis ao estado de humor dos humanos, reforçando o conceito de "computação afetiva" (Wortham, 2013) e levando ao que define Podoly (2015) no artigo O novo front dos vestíveis (tradução do autor) ${ }^{7}$ à uma "internet of me". Este é um novo recorte temático no qual a professora do MIT Rosalind Picard estuda as "formas de atribuir habilidades emocionais ao computador para que a máquina tenha capacidade de responder de forma inteligente às emoções humanas" (Leal, 2011, p.57). Nessa direção, reforçam-se estudos que avaliam as emoções dos usuários quando estes ficam em frente aos aparelhos. Na Revista Fapesp (2015), no texto Emoções catalogadas, a jornalista Dinorah Ereno relata a parceria do Instituto de Matemática e de Computação da USP/São Carlos com a UFSCar, no sentido de "captar expressões faciais" através de equipamentos que

poderão identificar as emoções do usuário, interpretá-las em tempo real e reagir de modo inteligente, sugerindo ações para alterar, por exemplo, um estado emocional indesejado ou reforçar um desejado (Ereno, 2015, p. 62).

As possibilidades das máquinas "afetivas" são inéditas e algumas das variáveis captáveis são a medição dos batimentos cardíacos, da pressão arterial, mas também da condutividade elétrica da pele das pessoas. Estes são conhecimentos muito úteis para, por exemplo, entender a"simpatia" das pessoas quando se deparam com produtos nas gôndolas, quando enfrentam situação imprevista de estresse, contrariedades em situações variadas e em importantes áreas como a medicina, educação etc., e no marketing, especificamente no relacionamento do consumidor com os produtos. As alterações físico-biológicas internas e sutilmente emitidas pelo corpo humano sinalizam o grau emotivo de aceitação, repulsa etc. quando o ser interage em diferentes situações. Estes são assuntos muito importantes para a comunicação, uma vez que esta pressupõe identificação cognitiva entre emissor e receptor.

Na questão da emotividade, Kurzweil (2007) aponta uma área desconhecida e pouco acessível do cérebro humano, mas que é suscetível a específicos tipos de estímulos. $\mathrm{O}$ autor relata experiências desenvolvidas por neurocientistas da Universidade da Califórnia, em San Diego/EUA que, ao

7 Tradução para "The next front of wearables". 
estudar padrões de epilepsia, "descobriram o que chamam de 'módulo de Deus', um pequeno lócus de neurônios no lobo frontal, que parece ser ativado durante as experiências religiosas" (Kurzweil, 2007, p. 211). Ele lembra que "uma base neurológica para a experiência espiritual tem sido postulada há muito tempo pelos biólogos evolucionistas" ${ }^{8}$ para mais adiante fechar o raciocínio ao afirmar que

com o próximo estágio de evolução criando uma nova geração de seres humanos, que será trilhões de vezes mais capaz e complexa do que os humanos de hoje, nossa capacidade de experiência espiritual e de insight provavelmente também ganhará em potência e profundidade (Kurzweil, 2007, p. 211)

A partir deste contexto e advogando que a sociedade vem evoluindo através da experimentação de inéditos processos de acesso, domínio e difusão de dados e conhecimento, algumas asserções empíricas se projetam no sentido de saber se, baseada em tecnologias perenes de toda ordem, a humanidade estaria mergulhando em simbioses e conectividades tecnológicas tão profundas que estas poderiam vir a se "fundir" aos seus processos cognitivos. Ou ainda, se integradas à estrutura psíquica humana, estas expandiriam as características biológicas humanas vindo a alcançar dimensões transcendentais, fato que ampliaria a forma de comunicação do ser para com instrumentos e outros seres. E, por último, se com este conjunto evolutivo se avizinha uma larga e profunda malha estruturada em dialogicidades mentais, estabelecendo um estágio complementar às redes "clássicas", aquelas conhecidas até o presente momento. Neste contexto, tais vetores comporiam cenários que conduziriam a sociedade na direção de uma total e profunda hibridização homem-máquina, condição na qual seriam partilhados processos comunicativos robustos entre mentes e máquinas, num patamar que poderia ser denominado de técnicobio-espiritual, como sugerem autores como Kurzweil (2007), Capra (1996), Minsky (1988, 2006) e Goswami (2008), entre outros. Isto se justifica tendo em vista as recentes descobertas sobre a evolução dos processos neuronais que, entre outras habilidades permitem, como já alcançado na Neurociência, a comunicação entre cérebros e máquinas a partir de implantes corpóreos sutis e perenemente conectados. Estes estabelecerão malhas tecnológicas que ligarão

8 Aqui se insere o conceito de Noética, como a disciplina que estuda os fenômenos da consciência, da mente, do espírito e da vida, a partir do ponto de vista da ciência. 
as mentes humanas aos aparelhos, exatamente como as máquinas fazem entre si através das conexões wi-fi de todos conhecidas.

Dessa forma, projetamos se, em idêntico processo, os equipamentos poderão conectar mentes humanas, através de processos de trocas de informação permitindo, através do pensamento, o intercâmbio de conteúdos. Estas são possibilidades que entendemos que devam ser continuamente investigadas, dado o frenesi da inventividade das inovações tecnológicas do momento. Ponderamos que o que parecia absurdo anos atrás, hoje integra a experiência humana cotidiana e a comunicação feita unicamente através do pensamento entre humanos e máquinas já existe, tendo sido realizada na área da neurociência, como abordamos a seguir.

\section{Máquinas que entendem pensamentos humanos}

A literatura indica que diferentemente das máquinas, o cérebro tem alguns processos ainda obscuros, o que requer estudos sobre as lógicas e os processos cerebrais para aprofundar o entendimento das relações humanosmáquinas. Isto é pertinente na elaboração de conhecimento sobre os adereços móveis que se acoplam ao organismo humano (tecnologias vestíveis) e executam comandos emitidos exclusivamente pelas mentes de seres no caso, aqueles com deficiências físicas.

Essas são investigações muito úteis para os estudiosos dos processos comunicativos do futuro e estão acontecendo nas experiências que focam a "exploração das interfaces cérebro-máquinas que tem provocado uma verdadeira corrida entre neurocientistas de todo o mundo" (Miranda, 2012, p. C5). Nessa área, já se destacam o sucesso das "próteses controladas apenas pelos pensamentos", ao revelar que comandos de máquina elaborados na mente de uma paciente, há muitos anos, tetraplégica, acionou uma mão robótica externa, a partir de eletrodos implantados no seu córtex motor.

Essa foi uma conquista importante, pois se trata do inédito fato de o comando ter sido emitido exclusivamente pelo cérebro de um ser humano e compreendido, a distância, em conexão via rede, por máquinas que decodificam e cumprem a ordem emitida. Isto, lembramos, se configura como um clássico processo de comunicação. Corroborando com essa explanação, no evento Technology, Entertainment and Design (TED) realizado em 2010, a cientista Tan Le apresentou o e-motiv, um sistema de tecnologias no segmento das Interfaces cérebro-computador (Brain computer interface technologies) que lê pensamentos humanos e os transmite à distância (Le, 2010). 
A partir do conhecimento alcançado nessas experiências científicas, indaga-se se tais pressupostos poderão ser aplicados nos processos da comunicação. Falamos da incorporação dos métodos de intercâmbios cognitivos, através do pensamento, na comunicação realizada entre seres e equipamentos nas atividades individuais de acesso e usufruto dos significados estocados nos repositórios informativos. Entendemos que poderá ser viável a estruturação de bases processuais com tal espectro analítico nos estudos comunicativos contemporâneos, uma vez que esses se baseiam na Teoria Matemática de Shannon e Weaver, que têm suas origens no mundo material da engenharia e balística.

Autores conceituados da comunicação estudaram e definiram as propriedades da emissão, transmissão e recepção de conteúdos de e para seres humanos, através de equipamentos de toda ordem. Assim, sabe-se que a comunicação e, por tabela, todo o processo industrial de criar, editar, arquivar e difundir conhecimento à sociedade está estruturado no mundo físico e concreto, aquele dos processos mecânicos, possível em sistemas interligados por fios elétricos, com máquinas que imprimem tintas em folhas virgens, com equipamentos que transmitem sinais em ondas de rádio para receptores de sons e imagens de toda ordem.

Reconhece-se que o acesso se dá com equipamentos físicos, palpáveis, e para que a "mágica" da comunicação aconteça sempre foi necessário a interação do ser humano, seja como emissor ou receptor, a partir do manuseio de equipamentos. Essa realidade durou longas décadas, até que com a chegada da informática (e dos aplicativos digitais em rede), variações ocorreram nos processos de produção e acesso às mensagens audiovisuais.

Em cenário que tudo alterou, máquinas de comunicação passaram a entender, além dos comandos de toques, também aqueles emitidos pela voz humana (Siri, tradutores instantâneos de textos falados etc.), dos gestos humanos (Kinect) e no início de 2015, a Apple patenteou o Eye-Tracking, que diagnostica os locais nos displays onde os olhos se concentram (Etherington, 2015). Trata-se da transmissão de comando mentalmente construído e que é enviado através de redes intraconectadas (como os sinais wi-fi), mas sem o toque humano em telas ou mediadores de sinais de entrada (teclados, controles remotos etc.), ou sem a voz ou gestos humanos. Reiteramos: só com a elaboração do pensamento, em processo que claramente poderia ser definido como telepatia digital. 


\section{As possibilidades de uma telepatia digital}

O termo telepatia é conhecido de outros segmentos do saber, tais como Física Quântica, Filosofia, Antropologia, Neurologia etc. Em nosso caso, foi "emprestado" da psiquiatria estando presente nos estudos da Psicofísica, onde cientistas tentam desvendar como se forma a consciência humana. No livro Decodificando o Universo, Seife adianta que ainda é difícil criar uma teoria para a telepatia, pois não se sabe que "mecanismos permitiriam que as mentes das pessoas se conectassem umas às outras" para em seguida afirmar que"a mecânica quântica parece oferecer um caminho: o emaranhamento" (Seife, 2010, p. 246). Para tanto, o autor discorre sobre os princípios da Teoria da Relatividade e da Teoria Quântica, assunto também abordado por Amit Goswami.

Na mesma direção, em A telepatia a través da internet está prestes a se tornar realidade (2014), a cientista Leslie Horn relatou a pesquisadores da Universidade de Washington que suas pesquisas "demonstraram com sucesso uma interface cérebro-a-cérebro em um estudo com seis pessoas. É a segunda versão desse estudo, [...] sendo suficiente para presumir que a telepatia poderá sair do mundo da ficção científica" (Horn, 2014). A investigadora descreve a experiência onde duas pessoas estavam em salas diferentes e não tinham como se comunicar, e uma delas

\footnotetext{
tinha o cérebro preso a uma máquina eletroencefálica que lia os sinais cerebrais [...] e ela só precisava pensar para mover sua mão [...] e isso era transmitido pela internet para o outro operador, cujas mãos estavam situadas em um touchpad e ele precisava tocar na posição certa conforme os sinais que passavam para ele (Horn, 2014).
}

Horn (2014) e os cientistas estão otimistas com a evolução dos estudos, pois os resultados alcançaram $83 \%$ de acerto e pretendem saber se, um dia, um professor conseguirá enviar informações diretamente para o cérebro de um estudante. Objetivamente, a pesquisadora almeja que um cérebro possa enviar conteúdos diretamente para outro cérebro, para o que depreendemos que não se trata da transmissão de linhas de comandos, mas sim do envio e recepção de mensagens com significados precisos.

Baseados no mesmo princípio, falamos da possibilidade de as pessoas acessarem mentalmente os variados meios de comunicação de massa, sem a necessidade "física" dos mesmos, alterando radicalmente toda a essência do processo comunicativo, aquele baseado em plataformas e aplicativos concretos para que a comunicação se efetue. Essa é a questão central da presente reflexão, pois se sabe que a síntese da comunicação consiste em codificar 
e enviar significados de um para outro ser humano, em processo que, na comunicação massiva, é intermediado por equipamentos onde os conteúdos de materializam (folha do jornal, páginas de livros e periódicos, tela do aparelho de TV, equipamento de rádio, etc.). Vale ressaltar que a comunicação homemmáquina, no caso aqui relatado, resume-se a frases mentais, sabendo-se que atualmente já foi alcançado estágio onde todo o processo se completa, pois já existe retorno em forma de mensagem emitida da máquina para o cérebro do emissor que, além de cumprir a ação demandada, passa detalhes do objeto analisado.

Essas tendências evolutivas poderão configurar radical mudança nas bases da comunicação humana, pois tais inovações eliminarão as interfaces que ainda hoje têm que intermediar os processos de envio e trocas de significados, sejam estes entre os homens ou entre as máquinas. Mas, sobretudo, entre máquinas e homens, realizando o feedback que os processos comunicativos tanto almejam. Quando possíveis estas descartarão a essência da atividade comunicacional "clássica", onde estão as empresas midiáticas que elaboram e vendem conteúdos informativos.

Neste novo cenário, as empresas deverão ser reconfiguradas, o que requererá que realizem processos profundos de reengenharia organizacional e de atuação midiática, se tornando fornecedoras de conteúdos virtuais alocados nas "nuvens", acessíveis o tempo todo, em multiplataformas, exatamente como fazem as empresas de informática. Este deverá ser o caminho inevitável, pois pelo menos no caso das emissoras de televisão, alterações inéditas já se instalaram na arte de produzir e assistir programas televisivo, conforme apontou Squirra (2013), ao indicar que a tendência é eliminar a grade de programação e a dependência dos intervalos comerciais. Dessa forma, nos EUA as três irmãs norte-americanas (American Broadcasting Company, $A B C$; Columbia Broadcasting Company, CBS e National Broadcasting Company, NBC) estão sofrendo profunda sangria com a chegada da NetFlix, da Amazon e recentemente com o PopCorn Time, que reinventaram a arte de produzir séries e conquistar audiências. Aliás, o processo tem demonstrado ser tão arrebatador que criaram o termo Binge-watching para definir aqueles que "não conseguem parar de assistir aos programas". Este fenômeno é irreversível e está permeando todos os cantos do globo, justamente por causa do acesso via aparelhos plenamente conectados que eliminam os modelos comunicativos do passado. Os conteúdos da televisão (termo que na realidade conectada deve ser trocado por cibervisão) agora estão na rede e à disposição de todos, o tempo todo. A velocidade da vida moderna requer interações mais rápidas e simples, 
em multiplicidades de exposição de conteúdos até então não experimentadas. Nesta seara conceitual, entendemos que a internet das coisas abriu caminho para uma internet de comandos mentais.

\section{Conclusões}

A evolução das inúmeras plataformas sinaliza que no futuro usando recursos tecnológicos incrustados no corpo, e através de comandos sincrônicos o homem será capaz de comunicar-se com a miríade de máquinas, inclusive aquelas onde estão estocados os relatos da comunicação. A oferta de tecnologias será continuamente ampliada, crescendo também a inteligência embutida nas máquinas, sinalizando que a relação de adesão e consequentemente de dependência do homem deve se intensificar. Tal processo configura simbiose incontornável, cenário onde as máquinas se encarregam das memórias e ações funcionais do cotidiano, liberando o ser para atividades mais criativas e evoluídas.

No campo da comunicação, se prevê que toda a área da "indústria cultural" (emissoras de rádio e de TV, jornais, revistas etc.) deverá ser "moída" pela evolução que se experimentará, uma vez que os processos comunicativos serão realizados sem os anteparos midiáticos que hoje se experimenta. As inovações tecnológicas romperão os processos comunicativos massivos como os conhecemos hoje, relações que se dão essencialmente com a intermediação de estáticos aparatos de materialização de conteúdos. A arte de consumir conteúdos (assistir televisão, ouvir rádio, ler jornal etc.) já está mudando no presente, uma vez que isto passou a se materializar nas variadas bases midiáticas móveis e conectadas, nos displays anteriormente falados. Neste cenário transmutado tudo se materializa em todos os lugares, o tempo todo, de todas as formas, em todos os sentidos. É, de fato, uma nova realidade, que alicerça o caminho para as formas comunicativas que se materializarão em processos mentais, incorporando as facilidades interativas já alcançadas na robótica e na neurociência. Falamos de um inédito momento onde os seres humanos, com o uso de tecnologias vestíveis ubíquas, passarão a consultar os repositórios noticiosos de jornais, emissoras de rádio e televisão etc. através de comandos mentais, sem nenhuma forma de explicitação física externa, contato ou interação com equipamentos que materializem os conteúdos estocados nos gigantescos repositórios de dados.

É neste cenário instigante que a comunicação se dará de cérebro para máquinas, e tão importante quanto, de máquinas para cérebros (pressuposto 
componente da inteligência artificial), sem as formas de mediação hoje praticadas. Neste último caso, o pesquisador Miguel Nicolelis em palestra do TED de outubro de 2014, com título A comunicação cérebro-a-cérebro justamente chegou (tradução do autor) ${ }^{9}$, afirmou que através de próteses neurocorticais, com equipamentos leitores eletroencefálicos era possível receber sinais de retorno (o feedback), pois o jogador que esteve na abertura da Copa podia "sentir o chão" em que pisava, lembrando que em pouco tempo nossos descendentes "poderão navegar pela rede só com pensamentos" (2014). Como diz Kurzweil (2007, p.344), "região por região, o cérebro e o sistema nervoso [...] serão transportados para a tecnologia computacional e, em última instância, substituirão aqueles órgãos de processamento da informação".

$\mathrm{Na}$ área da neurociência o que aqui projetamos já é plenamente possível, sobretudo quanto à comunicação linear e unidirecionada, produzida por pensamentos para membros robóticos acoplados ao corpo humano. O que projetamos é que isso poderá ser realizado no comando de máquinas que disponibilizem a fértil variedade de conteúdos alocados nas distintas bases midiáticas. Tais possibilidades consolidam o conceito de noosfera, momento no qual viver-se-á na plenitude dos intercâmbios mentais, pois como arremata Boff, a noosfera "expressa a convergência de mentes e corações, originando uma unidade mais alta e mais complexa" (2009). Na "esfera do pensamento humano", tal realidade evidencia alterações também onde estão incluídos os processos comunicacionais tais como hoje são conhecidos. Este é um tema instigante, aqui inicialmente abordado, mas que aguarda contribuições científicas que o levem à frente.

\section{Referências}

ANDERÁOS, Ricardo. O profeta das máquinas espirituais. Folha de S.Paulo, São Paulo, 13 nov. 2006. Caderno Link, p.10

BELL, Daniel. The third technological revolution and its possible socioeconomic consequences. New York: Dissent, Spring 1989. p. 184-176.

BOFF, Leonardo. O novo patamar da mundialização: a noosfera. Jun. 2009. Disponível em: <http://cartamaior.com.br/?/Coluna/O-novo-patamar-da-mundializacaoa-noosfera/19201>. Acesso em:_09 jul. 2009.

CAPRA, Fritjof. A teia da vida. São Paulo: Cultrix. 1996.

9 Tradução para "Brain-to-brain communication has just arrived. How we did it". 
CARR, Nicholas. The library of utopia. Technology review, May-Jun, 2012.

ERENO, Dinorah. Emoções catalogadas. Revista Fapesp. Edição de janeiro de 2015, p.62. Disponível em: <http://revistapesquisa.fapesp.br/wp-content/ uploads/2015/01ß/062-063 Estresse 227.pdf?458c41>. Acesso em: 22 mar. 2015.

ETHERINGTON, Darrell. Apple Patents Eye-Tracking And Visual Control Tech For Mac, iOS And Beyond. Jan. 2015. Disponível em: <http://techcrunch.com/2015/01/20/ apple-patents-eye-tracking-and-visual-control-tech-for-mac-ios-andbeyond/>. Acesso em: 20 mar. 2015.

GAMA, Ruy. A tecnologia e o trabalho na história. São Paulo: Nobel/Edusp, 1986.

GLEISER, Marcelo. $\mathbf{O}$ cérebro determina o que é real? Folha de S.Paulo, São Paulo, 13 nov. 2011. Caderno Ciência. Disponível em <http://www1.folha.uol.com. br/fsp/ciencia/8564-o-cerebro-determina-o-que-e-real.shtml>. Acesso em: 07.09.2014

GLEISER, Marcelo. Bem vindo ao trans-humano. Jun.2014. Disponível em: < $\underline{\text { http:// }}$ www1.folha.uol.com.br/colunas/marcelogleiser/2014/06/1466640-bemvindo-ao-trans-humanismo.shtml>. Acesso em: 18 dez. 2014.

GOSWAMI, Amit. A física da alma. S.Paulo: Aleph, 2008.

HABERMAS, Jurgen. Mudanças estruturais da esfera pública. São Paulo: Unesp, 2014

HALPERN, Sue. Cérebro: no controle ou controlado. O Estado de S.Paulo, São Paulo. Caderno Link/The New York Review of Books, 20.06.2011. Disponível em < $\underline{\text { http:// }}$ blogs.estadao.com.br/link/cerebro-no-controle-ou-controlado/>. Acesso em: 12 mar. 2014.

HORN, Leslie. A telepatia através da internet está prestes a se tornar realidade. nov. 2014. Disponível em: <http://m.gizmodo.uol.com.br/telepatia-pela-internet/>. Acesso em: 09 fev. 2015.

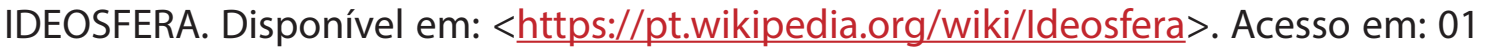
fev. 2015.

IZZO, João Artur. Noosfera e Midiosfera, o Imaginário humano e o engenho da mídia. 2009. Disponível em: <http://www.bocc.ubi.pt/pag/bocc-noosfera-joao. pdf>. Acesso em: 18 dez. 2014.

KURZWEIL, Ray. A era das máquinas espirituais. São Paulo: Aleph, 2007.

KURZWEIL, Ray. The law of accelerating returns. Mar. 2001. Disponível em: < http:// www.kurzweilai.net/the-law-of-accelerating-returns >. Acesso em: 20 fev. 2015.

LE, Tan. TEDTalks A headset that reads your brainswaves. Julho 2010. Disponível em: 
$<$ http://www.ted.com/talks/tan le a headset that reads your brainwaves $>$. Acesso em: 22 dez. 2011.

LEAL, Renata. Máquinas têm sentimentos? Revista Info, São Paulo: Abril 2011, p.57.

MACHADO, Irene (org.). Semiótica da cultura e semiosfera. São Paulo: Anablume, 2007.

MINSKY, Marvin. The society of mind. New York: Simon\&Schuster, 1988.

MINSKY, Marvin. The emotion machine. New York: Simon\&Schuster, 2006.

MIRANDA, Giuliana. Tetraplégica controla mão-robô com a mente. Folha de S.Paulo, São Paulo, 17 dez. 2012 Caderno Saúde + Ciência. Disponível em <http://www1. folha.uol.com.br/equilibrioesaude/2012/12/1202336-tetraplegica-controlamao-robo-com-a-mente.shtml>. Acesso em: 16 fev. 2014.

MORIN, Edgar. $O$ método 4: As idéias: habitat, vida, costumes, organização. Porto Alegre: Sulina, 2001.

NICOLELIS. Miguel. TED Talks Brain-to-brain communication has just arrived. How we did it. Out. 2014. Disponível em < http://www.ted.com/talks/miguel nicolelis brain to brain communication has arrived how we did it\#t938363>. Acesso em: 22 mar. 2015.

PENROSE, Roger. A mente nova do rei. Computadores, mentes e as leis da física. Rio de Janeiro: Campus, 1993.

PODOLY, Erez. The next front of wearables. Jan. 2015. Disponível em: $<$ http:// techcrunch.com/2015/01/28/the-next-front-of-wearables/>. Acesso em: 23 abr.2015.

SANTOS, Milton. A natureza do espaço. São Paulo: Edusp, 2008.

SEIFE, Charles. Decodificando o universo. Rio de Janeiro: Rocco, 2010.

SILVA, Fábio de Barros. Teilhard de Chardin: a ideia de evolução e vida pessoal. 1999. Disponível em: <http://www.ufsj.edu.br/portal-repositorio/File/table/ revista metanoia material revisto/revista01/trexto03 evolucao thellard de chardin.pdf>. Acesso em: 14 jan. 2015.

SQUIRRA, S. O futuro da TV na fusão tecnológica que tudo altera. Revista de Radio Difusão da SET-Sociedade de Engenharia de TV, vol.7, no.7, 2013, p. 21-27. Disponível em: < http://www.set.org.br/revistaderadiodifusão>. Acesso em: 13 fev. 2014.

STERNBERG, Robert. Psicologia cognitiva. São Paulo: Cengage Learning, 2013.

TENÓRIO, Robinson M. Cérebros e computadores. São Paulo: Escrituras, 2001. 
TOFFLER, Alvin. A terceira onda. Rio de Janeiro: Record, 1980.

WIENER, Norbert. Cibernética e sociedade - $\mathbf{O}$ uso humano de seres humanos. São Paulo: Cultrix, 1954.

WORTHAM,Jenna.Computação afetivamira emoções.FolhadeS.Paulo/NYT.Jun.2013. Disponível em <http://www1.folha.uol.com.br/fsp/newyorktimes/114491quotcomputacao-afetivaquot-mira-emocoes.shtml>. Acesso em: 14 jun.2014.

Recebido em: 6/7/2015

Aceito em: 9/9/2015

Endereço do autor:

Sebastião Carlos Squirra <ssquirra@gmail.com>

Faculdade de Comunicação da Universidade Metodista de São Paulo (UMESP).

Rua Alfeu Tavares, 149 - Campus Rudge Ramos

09641-000 - São Bernardo do Campo - SP - Brasil 